\title{
Experimental Study on Mechanical Property of Corner Columns Supported Reinforced Concrete Honeycombed-core Girderless Floor
}

\author{
Weijun Yang ${ }^{1, *}$ Yongda Yang ${ }^{1}$ Bing Han $^{2}$ and Pengxiao Jiang ${ }^{1}$ \\ ${ }^{1}$ Changsha University of Science and Technology, Changsha, Hunan, 410114, China \\ ${ }^{2}$ Transport Management Institute Ministry of Transport of the People'Republic of China, Peking, 065201, China
}

\begin{abstract}
In order to study the basic mechanical property of the new honeycombed-core girderless floor in cast-in-place reinforced concrete, and similarities and differences of the structural performance compared with traditional floor, we carried out the destructive stage loading test on large-scale corner columns supported reinforced concrete honeycombed-core girderless floor. And the thesis conducted finite element analysis in virtue of ANSYS software for solid slab floor, rib floor and honeycombed-core floor. The experiment indicates that honeycombed-core modules cement well with concrete around and participate in the load-carrying; the developing process, distribution and failure mode of crevice in honeycombed-core floor are similar to that of general solid girderless floor. The honeycombed-core girderless floor has higher bearing capacity and better plastic deformation capacity. The finite element analysis manifest that compared with solid slab floor, honeycombed-core floor's dead load decreases on greater level while deformation increases little, and that compared with rib floor, honeycombed-core girderless floor has higher rigidity. So reinforced concrete honeycombed-core girderless floor is particularly suitable for long-span and large-bay building structure.
\end{abstract}

Keywords: honeycombed-core module; reinforced concrete honeycombed-core girderless floor; mechanical property; experiment study; finite element analysis (FEA).

\section{INTRODUCTION}

The cast-in-place girderless hollow floor is a new floor endowed with merits of small structural height, light deadweight, convenient construction, etc. In the past, study on the hollow floor in China is mainly concentrated in the hollow floor with circular hollow tube inside [1 6]. With the thin tube as filling component, the hollow girderless floor will form the one-way channel like the hole-hollow plate, which causes the differences in aspects of shape and momento finertia between plate cross-section perpendicular to pore canal and that parallel to pore canal, and the later plate cross-section will change with the different positions of the cross section. The column grids of girderless floors are usually square or close to the square. Under the action of vertical load, the plates appear compound bending, and flexural capacity in both directions is roughly the same. As a result, the method of one-way pore-forming with thin-walled tube is conflictive to the property of biaxial bending of girderless floors. Then, hollow ratio of floor slab obtained in such situation is lower. If solid section around floor is taken into consideration, the hollow ratio of the whole floor is even less than $20 \%$.

*Address correspondence to this author at the Changsha University of Science and Technology, Changsha, Hunan, 410114, China;

Tel: +86-731-85258197; Fax: +86-731-85258197;

E-mail: mgbyrh@163.com
In allusion to the defect that round-tube girderless floors have different mechanical properties of bending and shearing in both span directions, China has independently developed a bi-directional orthogonality ribbed I-shaped girderless floor-technique of honeycombed-core girderless floor in cast-in-place reinforced concrete $[7,8]$. This technique adopts honeycombed-core series of internal molds to form inner-space load carrying unit in the cast-in-place concrete slab, and to configurate a clear-load-transmission horizontal structural system of bidirectional gridding ribbed hollow floor, which can form a space structure system assorting with hidden beam, flat beam or visible beam, shown as Fig. (1). [9, 10]. At present, studies on such floor system are still relatively poor, and its mechanical property and analytical method are

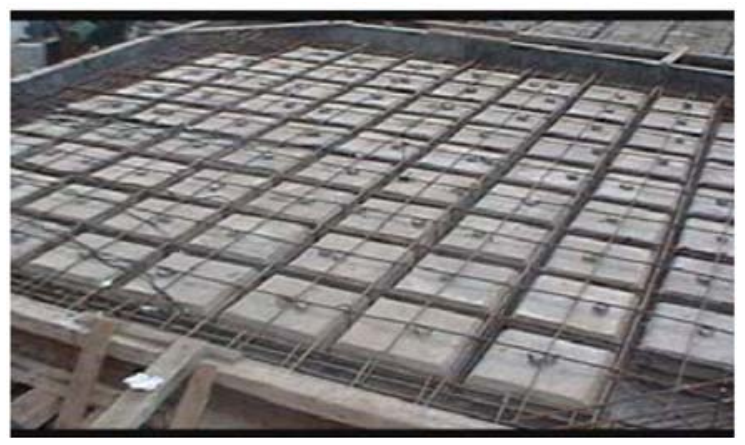

Fig. (1). Reinforced concrete honeycombed-core girderless floor. 
still far from perfect. The projects having been put into use typically follow the design method of rib floor without consideration of influence of the honeycombed-core mode. In these projects, the amount of reinforcing steel is increased blindly, which not only brings about waste of materials, but increases the difficulty of construction. This paper carried out the destructive test of the honeycomb-core floors with 4-corner point fixed bearing in the short-term loading condition, and obtained the knowledge of the structural performance in the whole process of bearing capacity of developing process, deformation characteristics and failure mode of such type of floor. Then, through the finite element analysis on the basis of ANSYS, the finite element model of solid slab floor, rib floor and honeycombed-core floor with the same size with each other. The strength performance is analyzed in the elastic stage. The study manifests that honeycombed-core floor is endowed with higher structural rigidity, superior property of stress deforming, higher bearing capacity and plastic safety margin.

\section{INTRODUCTION OF THE EXPERIMENT}

\subsection{Test Objective and Specimen Making}

The static test of the angular point fixed two-way slab measured the stress, strain, deflection and crack distribution under different class of loading, and also, determined the ultimate bearing capacity of such kinds of floor. In this process, the failure characteristic was observed.

The plane size of the test floor is $4250 \mathrm{~mm} \times 4250 \mathrm{~mm}$; thickness of slab is $160 \mathrm{~mm}$, in which faceplate thickness is $40 \mathrm{~mm}$. The dimension of honeycomb-core internal mold is $350 \mathrm{~mm} \times 350 \mathrm{~mm} \times 120 \mathrm{~mm}$, in which the bottom-slab thickness is $10 \mathrm{~mm}$, the wall of honeycombed-core modules is about $5 \mathrm{~mm}$. The reinforced concrete columns are set up at four corners of the floor; the size of column section is

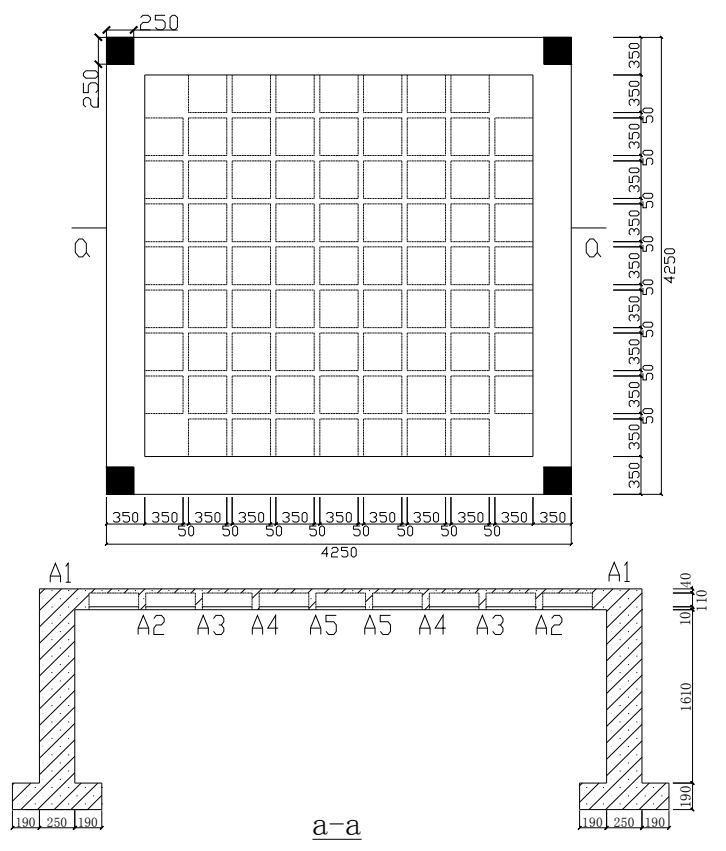

Fig. (2). Structure and size of honeycombed-core floor.
$250 \mathrm{~mm} \times 250 \mathrm{~mm}$. In order to prevent the punching failure in the bracket, the section round bracket is designed as solid structure; and herein furnishes reinforcing steel bar to resist punching failure, shown as Fig. (3a). In order to facilitate observation of the deflection and cracks, the height of column is supposed as $1.8 \mathrm{~m}$. Fig. (2) shows the structural style and arrangement of the floor model. The deadweight of the floor model is designed to $2.57 \mathrm{kN} / \mathrm{m}^{2}$; standard external load $2 \mathrm{kN} / \mathrm{m}^{2}$. This model carries out internal force calculation and reinforcing bars according to ribbed floor. The designing label of concrete is C25; location of reinforcement of floor inside is presented in Fig. (3b). The trial model is completed in test room, which is casted into shape by commercial concrete, and is maintained naturally indoor.

\subsection{Test Methods}

The test adopts bricks and weights to load simultaneously. Each brick weighs $24 \mathrm{~kg}$ (average value of ten bricks in random sampling). Bricks and weights are piled up on the floor to imitate the uniform load. If the loading materials are stacked on the surface of the structure directly, the loading materials

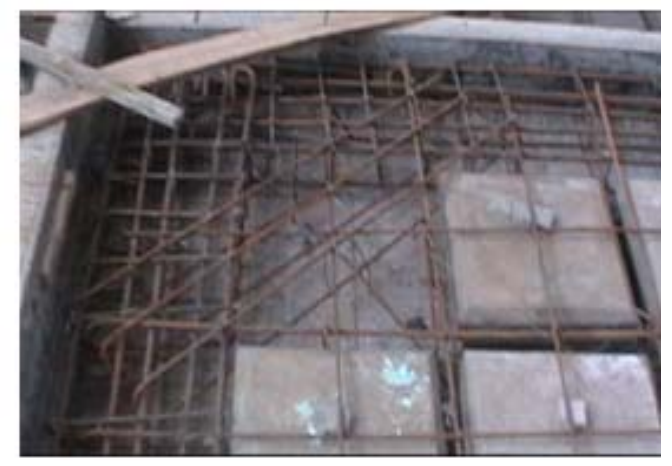

(a)

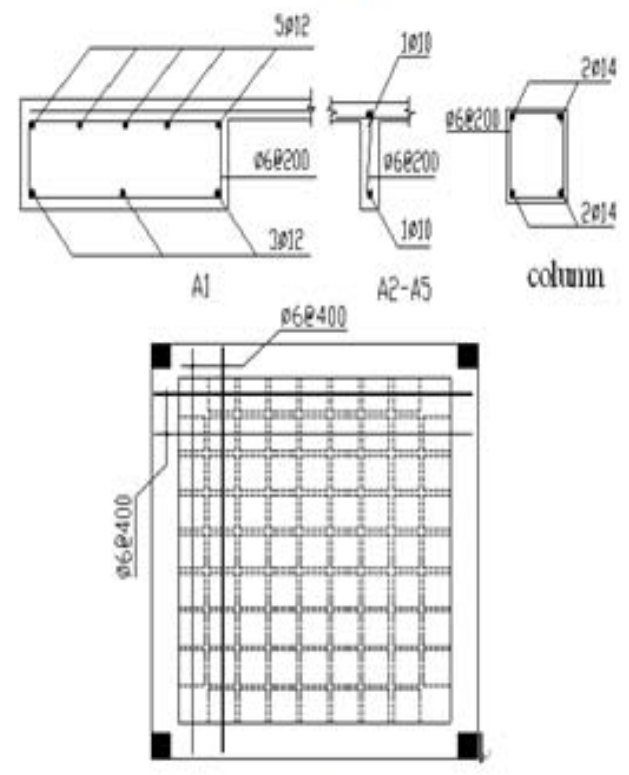

(b)

Fig. (3). Distributed steel of honeycombed-core floor. 


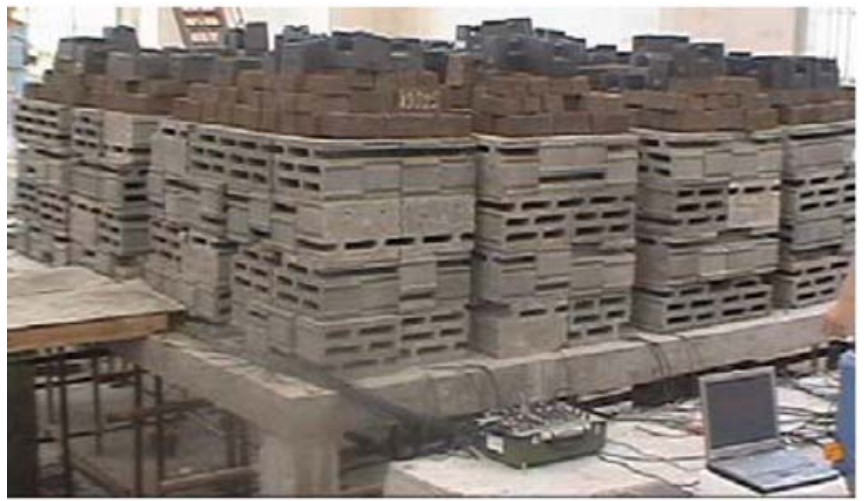

Fig. (4). Loading of honeycombed-core floor.

themselves will be caused arch camber, which can bring about unloading effect for the structure [8]. As a consequence, the loading adopts the form of $4 \times 4$ brick piers with $133 \mathrm{~mm}$ distance among piers. Fig. (4) shows the concrete form.

Since this floor is orthogonal and same nature board and has symmetry, measuring points are mainly arranged in the grids of $1 / 4$ Zone. Besides, symmetry point is set at the key points. The deflection value is measured by dial test indicator. After centering adjustment at measuring point, the dial indicators are fixed on the steel tubes of the supporting frame through magnet stand. To facilitate the process of deflection value, initial reading of the dial indicator is set to zero before test. The dial indicators measuring column sedimentation are placed above the floor, the rest of which are fixed below the floor. The positions of dial indicators are illustrated in Fig. (5a). Readings are recorded on different degree of load grade. On the basis of the analysis of deflection change, it indicates the carrying capacity and rigidity of the floor at each stage of elastic plasticity. As illustrated in Fig. (5b, c), strain foil of steel and concrete is set at following points on the surface of steel and concrete inside the floor.

The influence of temperature is eliminated through public compensation method. The strain data of steel and concrete on different degree of load grade is collected by data acquisition unit (7V14c) so as to analyze their strain change of floor from elastic stage to plastic stage. There exists a static duration of 15 20 min after each loading. The crack developing state of components will not be observed until deformation and cracks of the floor become stable. Meanwhile, record the deflection value and strain. Table $\mathbf{1}$ is the loading program.

\section{EXPERIMENTAL PHENOMENA AND ANALYSIS}

\subsection{Cracks and Failure Mode of the Honeycomb-core Floor.}

At the first level of loading, there appears no crack, and both deflection and strain are very small, which indicates that it is basically at the elastic stage. At the second loading level, micro-cracks appear at the place of honeycombed-core model in the middle part of the bottom plate and at the joints of core model and the rib; meanwhile, there also appears cracks on the top columns at the side of floor; the deflection at this level demonstrates non-linear growth, which can be considered that the floor begins to step into elastic-plastic stage. Until the third level, there emerge a number of cracks, and the original ones continue to become longer and connect with the new cracks; but the width of all cracks is not large. The oblique course of the top columns presents more cracks, width of which also increases. While at fourth stage of loading, several vertical and horizontal cracks on the bottom-slab are perpendicular through each other, and concentrate in the area of stepping middle boarding, and present symmetry in both two directions; at this time, the widest crack appears at the joint of
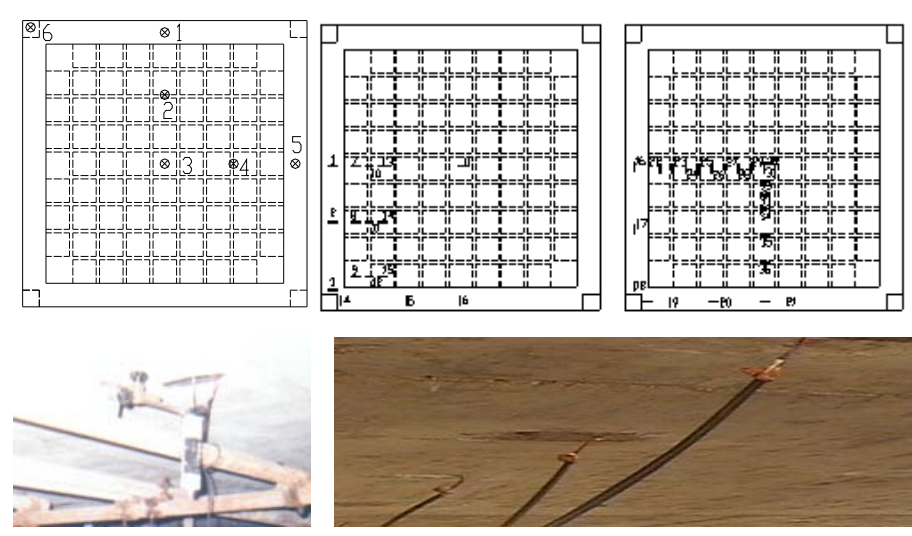

(a)

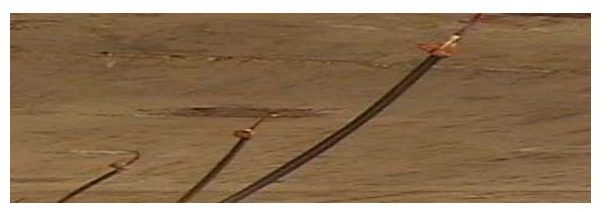

(b)
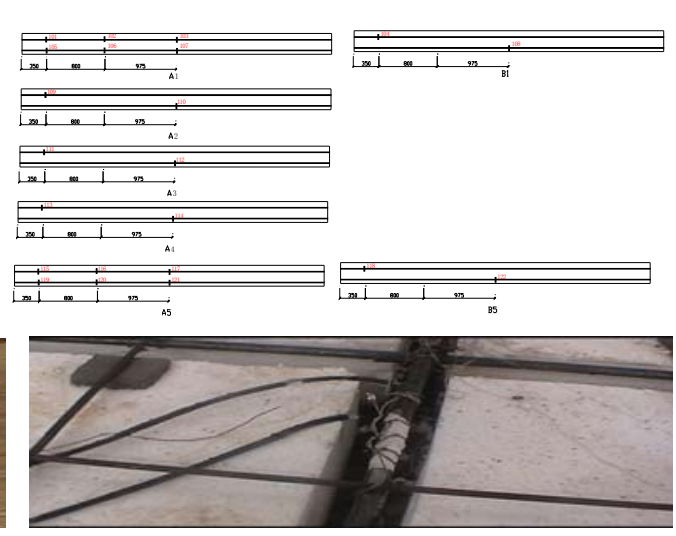

(c)

Fig. (5). Measuring point arrangement.

Table 1. List of Stepped Load

\begin{tabular}{|c|c|c|c|c|c|c|c|}
\hline Stepwise Loading & 1 & 2 & 3 & 4 & 5 & 6 & 7 \\
\hline Load per step $\left(\mathrm{kN} / \mathrm{m}^{2}\right)$ & 2.4 & 2.4 & 2.4 & 2.4 & 1.2 & 1.2 & 0.6 \\
\hline accumulative total load $\left(\mathrm{kN} / \mathrm{m}^{2}\right)$ & 2.4 & 4.8 & 7.2 & 9.6 & 10.8 & 12 & 12.6 \\
\hline
\end{tabular}


honeycomb-core model in the middle row and rib with width of $0.19 \mathrm{~mm}$, which is close to maximum crack width in common use; meanwhile, a crack at the bottom-slab of the middle hidden beam began to enter the board side. Data of acquisition system illustrate that numerical value of most concrete strain gauge of the bottom-slab has overflow; the concrete of bottom-slab are out of work on a whole; the steel strain increases a lot; the pulling fore is mainly provided by reinforcing steel bar. Under the condition of the fifth grade loading, the maximum width of cracks on the bottom-slab gets to the point of $0.38 \mathrm{~mm}$. At the sixth stage of loading, its maximum width of cracks reach to $0.48 \mathrm{~mm}$, and the deflection increases in speed. After the seventh stage of loading is added, and through a static duration of 20min, the maximum crack width is $0.81 \mathrm{~mm}$, and then, with the floor appearing crackling sound, concrete is peeling. Stop loading, and deformation grows rapidly. After a static duration of 2 hours, the deformation tends towards stability. At this time, the crack width achieves to $1.73 \mathrm{~mm}$, which can be reckoned that the floor has been destroyed. In the destruction, the middle part of bottom-slab appears cracks intersected vertically and horizontally. The failure mode is similar to that of common solid slab of girderless floor. Except the column head, cracks are not found in the remaining parts of the top-slab. Fig. (6) is the failure mode and actual crack distribution of the floor.

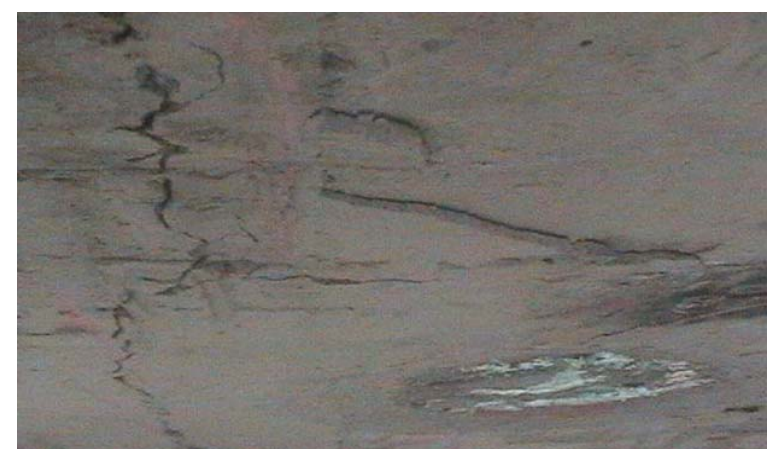

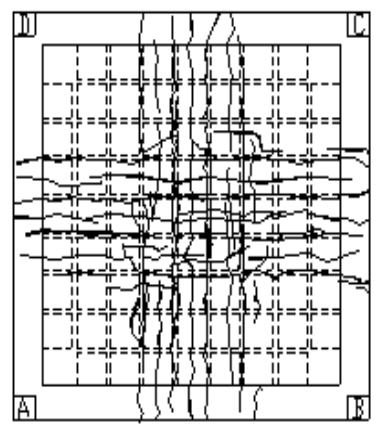

(a) bottom

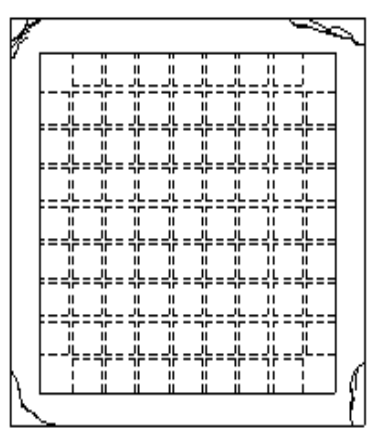

(b) top

\subsection{Stress Deforming Analysis of the Honeycomb-core Floor}

Table 2 presents the cracking load and failure load of the test floor. The ratio of failure load and standard load is 3.32, which illustrates that such kind of floor structure has some advantages to some extent, though the failure load is also related to many other factors, such as reinforcing bars. From the serviceability limit state (Maximum crack width of $0.2 \mathrm{~mm}$ ) to failure stage, the ratio of failure load and serviceability limit state load is 1.247 , which indicates that this floor is endowed with better plastic properties, compared with the common RC floor systems.

The load - deflection curve of each measuring points is presented by Fig. (7) to Fig. (9). Fig. (7) is the mid-span deflection curves; Fig. (8) is 1/4-span deflection curves; and Fig. (9) is hiding-beam mid-span deflection curves. It can clearly be seen that critical load that the floor gets into the plastic stage from elastic stage is above and beyond standard load. As a result, the floor stays in the state of elastic force balance on the whole.

Fig. (10a) and Fig. (10b) illustrate the deflection distribution and actual deformation of the floor under the failure loads respectively.
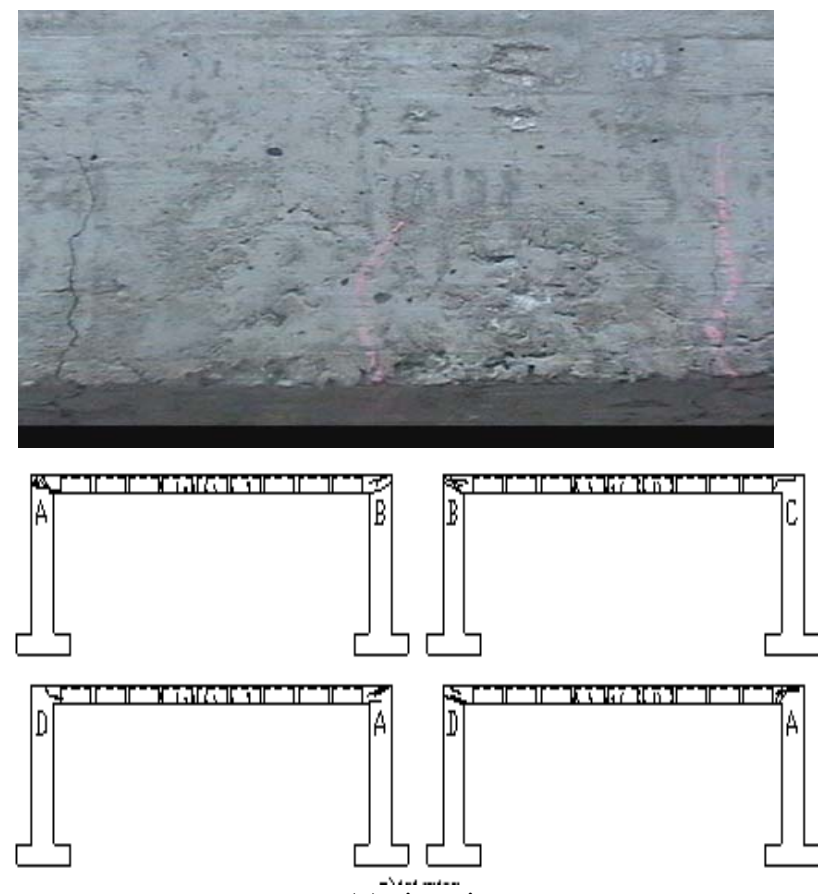

(c) interior

Fig. (6). Failure mode and actual crack distribution of the floor destroyed.

Table 2. Cracking Load, Failing Load and Safety Stock $\left(\mathrm{kN} / \mathrm{m}^{2}\right)$

\begin{tabular}{|c|c|c|c|c|c|}
\hline \multirow{2}{*}{$\begin{array}{c}1 \\
\text { Standard Load }\end{array}$} & 2 & $\begin{array}{c}3 \\
\text { Load when Maximal } \\
\text { Crack width is 0.2mm } \\
\mathbf{k N / m 2}\end{array}$ & $\begin{array}{c}4 \\
\text { Failing Load }\end{array}$ & Cracking $2 / 1$ & Failing $4 / 1$ \\
\cline { 3 - 6 } & 7.37 & 12.17 & 15.17 & 1.61 & 3.32 \\
\hline
\end{tabular}




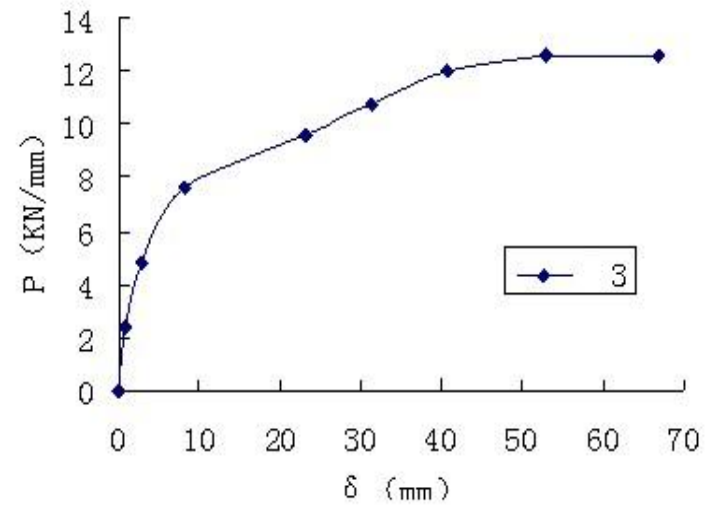

Fig. (7). Midspan deflection curves Fig.8 1/4-span deflection curves.

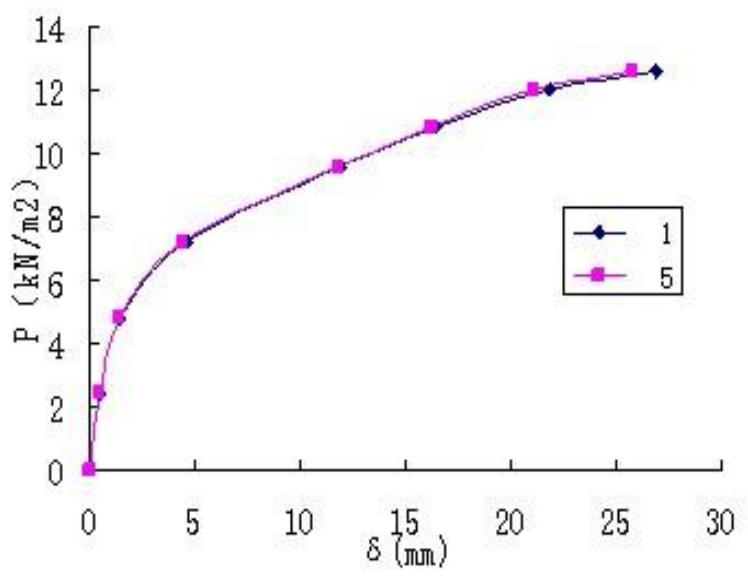

Fig. (8). 1/4-span deflection curves.

Since the cracks of test floor during service stage mainly concentrate at the midspan of bottom-slab, rigidity of crossing-section declines a little more obviously. While the width of cracks on the joint columns gets to $0.2 \mathrm{~mm}$, maximum deflection of midspan is $23.06 \mathrm{~mm}$, which has exceeded the permissible value of $20 \mathrm{~mm}(\mathrm{l} / 200)$ prescript in the specifications. At the failure stage, tension reinforcement does not reach to the yield stress. However, deflection of midspan at failure stage is $67.01 \mathrm{~mm}$, less than the damage standard of

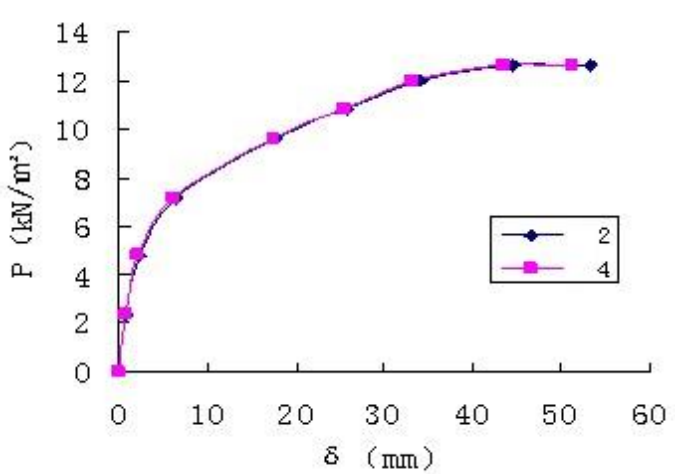

Fig. (9). Hiding-beam midspan deflection curves.

$80 \mathrm{~mm}(1 / 50)$ provided in structural test. Further, floor strip in midspan all appears vertical and horizontal orthogonal major cracks, which develop rapidly and with large width. So at the failure stage, cracks become the main objects in the designing checking computations.

\subsection{Steel-Concrete Strain Analysis of the Honey- comb-core Floor}

Concrete strain gauges of No. 22, 24, 25, 26, and 27 are arranged at the longitudinal midpoint of the ribs or cases. Fig. (11) shows their strain change trend.

From the strain of No. 107, 110, 112, and 121, it can be seen that the strain at longitudinal reinforcement midpoint underside each rib becomes larger with approaching to middle area. The trend is presented in Fig. (12).

The strain value of concrete indicates that concrete of top-slab are basically located in compressive region; the middle part bears the maximum pressure; hidden beams receive small pressure or tension; the concrete round columns stay in the state of tensile deformation apparently. Concrete tensile region of bottom-slab concentrate in the mid-span $1 / 2$ strip, but the edge is in the state of compression; there exists an area round the column that the compressive stress increases extremely. The stress circumstance of the concrete round the

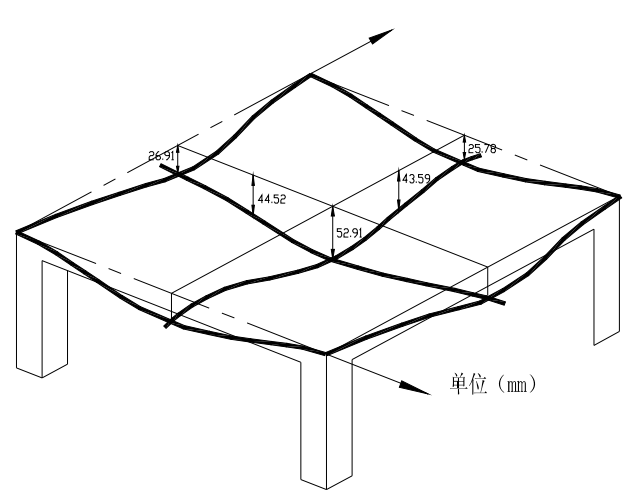

(a)

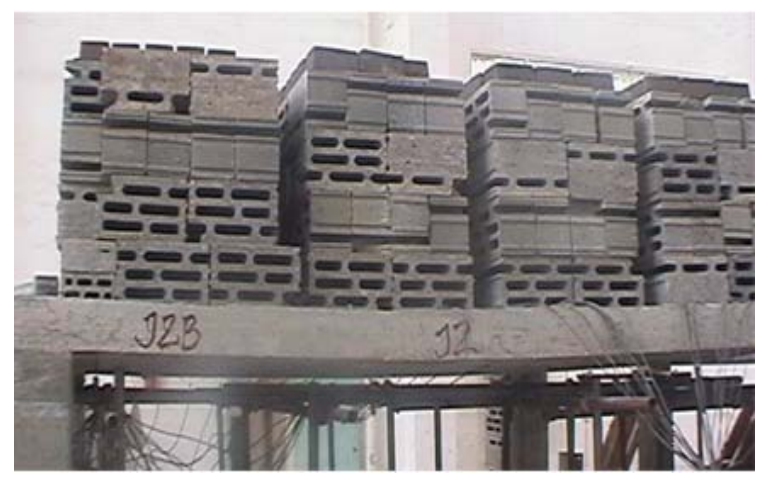

(b)

Fig. (10). Deforming of the floor under the seventh load. 


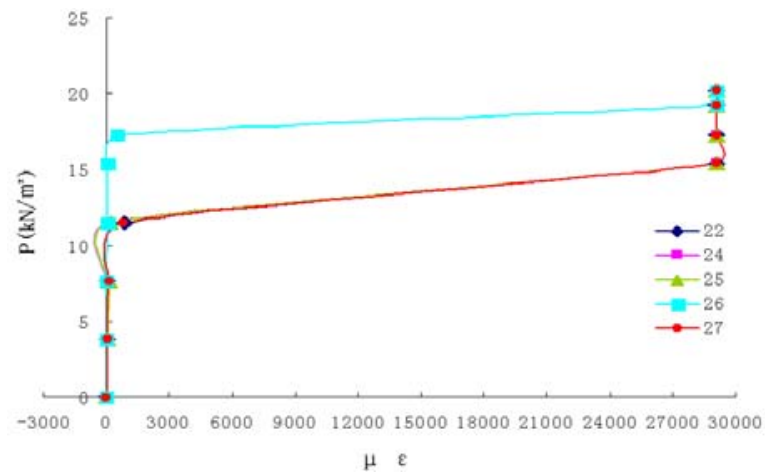

Fig. (11). Load - strain curve of concrete.

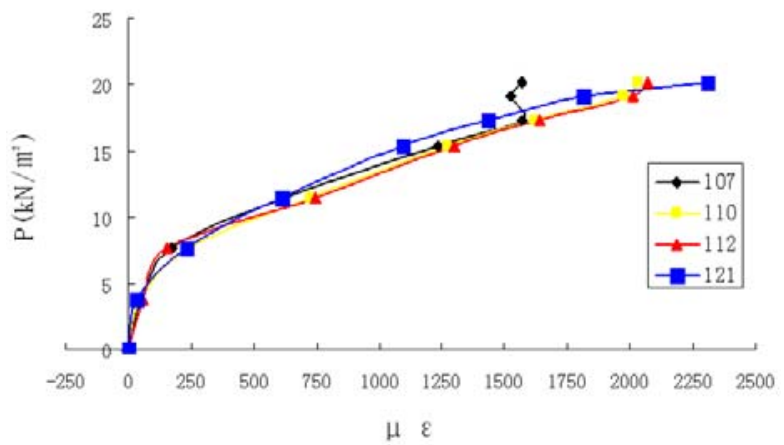

Fig. (12). Strain trends of reinforced midpoint.

column is a little complicated. There exists the phenomenon of stress concentration. So a range of solid area and more reinforcing steel should be adopted around the columns in designing. Reinforced strain data obtained from test demonstrate that the reinforcing steel bars contribute more to the tension of the floor, but little to the pressure. On the whole, the strain distribution is basically agreeable with that of solid girderless floor, and the strip division can apply strip division theory of common solid girderless floor mechanically.

\section{FINITE ELEMENT ANALYSIS OF THE HONEY- COMB-CORE FLOOR}

\subsection{Finite Element Model}

In virtue of ANSYS software, the finite element model of honeycomb-core floor, which is identical to the test model from aspects of structure and size, is established to carry out the finite element analysis to shape a compression with the test results. Meanwhile, to compensate for the trial deficiencies caused by limited conditions, solid floor model and ribbed floor model, both of which has the same support conditions and external dimensions, are set up, by which contrastive analysis with honeycomb-core floor can be conducted in order to obtain a deep knowledge of mechanical properties of honeycomb-core floor. The plane size of the finite element model is $4250 \mathrm{~mm} \times 4250 \mathrm{~mm}$; slab thickness is $160 \mathrm{~mm}$. The mandrel size of honeycomb-core floor is $350 \mathrm{~mm} \times 350 \mathrm{~mm} \times$ $120 \mathrm{~mm}$, with bottom-slab thickness of $10 \mathrm{~mm}$, rib spacing of $50 \mathrm{~mm}$, the upper solid plate thickness of $40 \mathrm{~mm}$. The ribbed floor has no bottom-slab. In order to make clear observation,

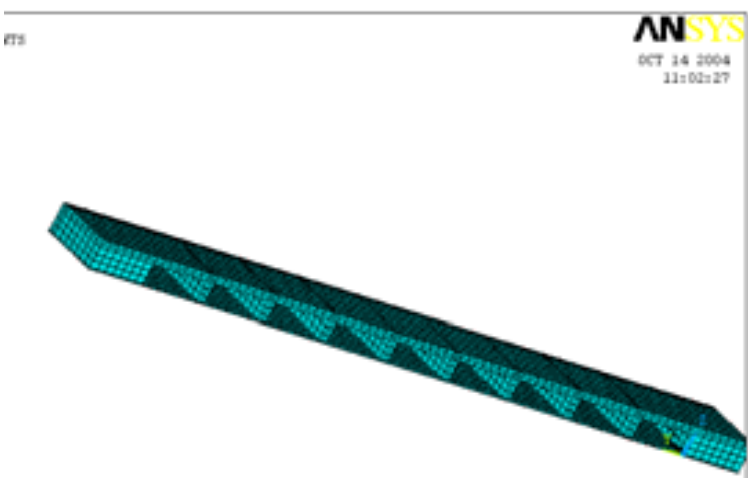

$\mathbf{N}$ $4=2000$

Fig. (13). Honeycombed-core floor.

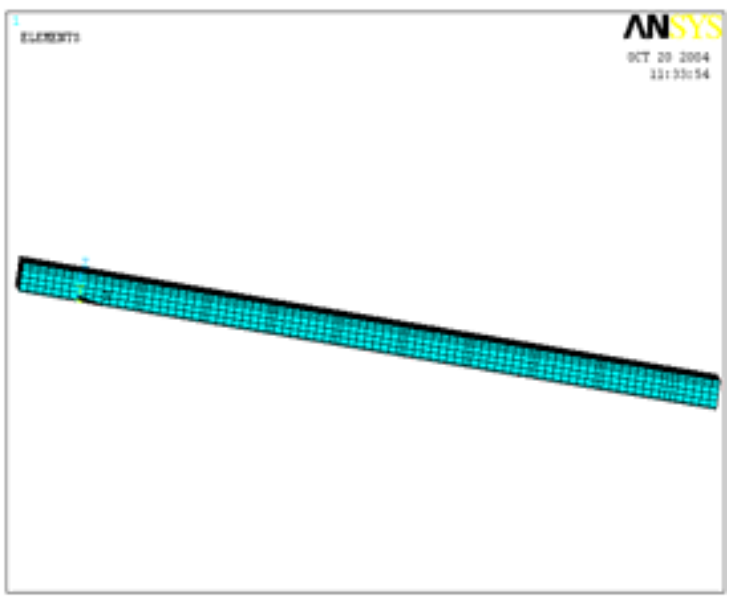

Fig. (14). Solid floor.

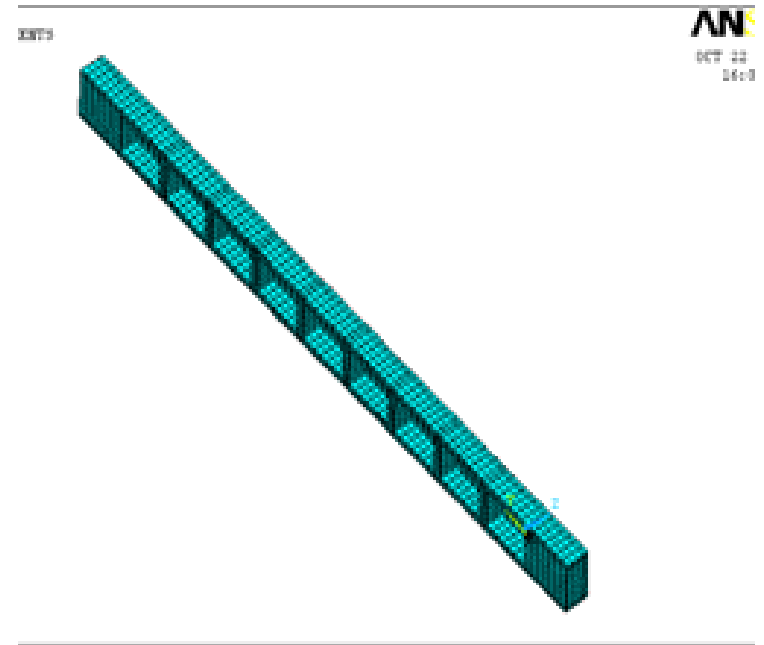

Fig. (15). Multi-ribbed Floor.

it only presents part of structure of finite element models of honeycomb-core floor, solid floor and ribbed floor, shown in Figs. (13-15). The 8-node isoparametric element, SOLID45, is adopted as its element type, with elasticity modulus $E X=E Y=E Z=2.8 \times 10^{10} \mathrm{~Pa}$, Poisson's ratio $\mu=0.2$. To facilitate 
the description, there forms a unified convention: the face slab is $x-y$ geometric plane surface, and the direction of plate thickness is Z-axis direction.

\subsection{Results of Finite Element Analysis}

\section{(1) Deflection Analysis}

Table $\mathbf{3}$ is the comparison between test deflection values and finite-element deflection values under the uniform load of $2.4 \mathrm{kN} / \mathrm{m}^{2}$. In the process of test, since the dial test indicator is installed up after finishing casting and removal of frame, the deflection value measured does not include the deflection under the influence of deadweight of floor. As a consequence, finite-element calculated value in Table $\mathbf{3}$ is the deflection under the uniform load of $2.4 \mathrm{kN} / \mathrm{m}^{2}$ without consideration of deadweight.

From Table 3, the deflection from finite element calculation of honeycomb-core floor is very close to experimental value, with the average error of $9.9 \%$. In addition, the deflection of honeycomb-core floor is smaller than that of ribbed floor in evidence. So it is safe to calculate the deflection of honeycomb-core floor according to theories of ribbed floor, but can cause large waste [10]. The box-type section improves the rigidity of floor greatly. If the finite-element deflection of solid floor is regarded as a benchmark, the deflection of honeycomb-core floor presents a difference of only $31 \%$ compared with that of the same thickness of the solid floor. However, rigidity of the rib floor with the T-shape section is small, and its deflection differs by $77.8 \%$ compared with that of solid floor with the same thickness. This fully reflects the advantage of the honeycomb-core floor.

Considering the deadweight of the floor, Table $\mathbf{4}$ shows the reduced value of deflection of honeycomb-core floor, rib floor, and solid floor under the external load of $2.4 \mathrm{kN} / \mathrm{m}^{2}$. From the table, deflection of the honeycomb-core floor declines much more with a very small increase of the deadweight, compared with rib floor, which indicates that this structural style has good rigidity. In comparison with solid floor, the deadweight of honeycomb-core floor decreases sharply while deflection does not increase much. Therefore,

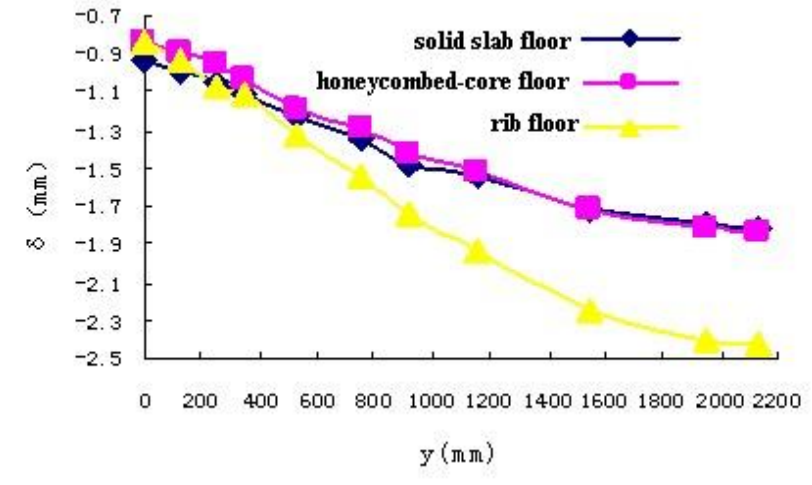

Fig. (16). Comparison of deflection alteration of crossing-section of three floors.

such structure form has obvious advantages in the project.

And then, Table 5 and Fig. (16) is comparison of deflection alteration of crossing-section of three floors. Through Fig. (16), the deflection change of honeycomb-core floor along span is rather close to that of solid floor; merely, its deflection in midspan area increase more rapidly than that of solid floor, but presents uniform change on a whole, which reflects that the honeycomb-core floor shows good overall distortion performance, and has higher rigidity. However, the deflection inboard of rid floor grows extremely rapidly. It indicates that the bending rigidity of such floor is smallest among these three floors.

\section{(2) Stress Analysis}

Fig. (17-20) are the stress nephogram of the honeycomb-core floor after finite element model is loaded. It is clear that the stress in X-direction is identical to that in Y-direction, but they are observed from different directions. Therefore, we can just study the stress from only one direction.

Some key sections are chosen to analyze the stress distribution. The key sections include crossing-section, hidden-beam section, hollow part of 1/4-span, and solid rib of 1/4-span, shown as Fig. (21-24).

Table 3. Comparison of Experimental Values and Finite Element Values of Deflection

\begin{tabular}{|c|c|c|c|c|}
\hline \multirow{2}{*}{ Deflection Values (mm) } & \multirow{2}{*}{ Test Value } & \multicolumn{3}{|c|}{ Results of Finite Element Analysis } \\
\cline { 3 - 5 } & & Honeycombed-Core Floor & Solid Slab Floor & Rib Floor \\
\hline \hline midspan & 0.83 & 0.748 & 0.571 & 0.015 \\
\hline hiding-beam midspan & 0.45 & 0.416 & 0.368 & 0.47 \\
\hline $1 / 4$-span & 0.69 & 0.621 & 0.544 & 0.813 \\
\hline
\end{tabular}

Table 4. Deflection Values Comparison Considering Dead Load

\begin{tabular}{|c|c|c|}
\hline Types & Maximum Deflection Value $(\mathbf{m m})$ & Ratio \\
\hline \hline solid slab floor $\left(7.6 \mathrm{kN} / \mathrm{m}^{2}\right)$ & 1.807 & 1.000 \\
\hline honeycombed-core floor $\left(5.884 \mathrm{kN} / \mathrm{m}^{2}\right)$ & 1.833 & 1.014 \\
\hline rib floor $\left(5.716 \mathrm{kN} / \mathrm{m}^{2}\right)$ & 2.417 & 1.338 \\
\hline
\end{tabular}


Table 5. Comparison of Deflection Alteration of Crossing-Section

\begin{tabular}{|c|c|c|c|}
\hline \multirow{2}{*}{ Location } & \multicolumn{3}{|c|}{ Deflection Value of Midspan $(x=2125 \mathrm{~mm})$} \\
\hline & Solid Slab Floor & Honeycombed-Core Floor & Rib Floor \\
\hline $\mathrm{y}=0 \mathrm{~mm}$ & 0.939 & 0.831 & 0.839 \\
\hline $\mathrm{y}=130 \mathrm{~mm}$ & 0.994 & 0.895 & 0.930 \\
\hline $\mathrm{y}=250 \mathrm{~mm}$ & 1.050 & 0.958 & 1.071 \\
\hline $\mathrm{y}=350 \mathrm{~mm}$ & 1.107 & 1.023 & 1.120 \\
\hline $\mathrm{y}=525 \mathrm{~mm}$ & 1.223 & 1.192 & 1.325 \\
\hline $\mathrm{y}=750 \mathrm{~mm}$ & 1.338 & 1.291 & 1.540 \\
\hline$y=925 \mathrm{~mm}$ & 1.475 & 1.420 & 1.745 \\
\hline $\mathrm{y}=1150 \mathrm{~mm}$ & 1.551 & 1.523 & 1.937 \\
\hline $\mathrm{y}=1550 \mathrm{~mm}$ & 1.713 & 1.724 & 2.240 \\
\hline $\mathrm{y}=1950 \mathrm{~mm}$ & 1.799 & 1.823 & 2.400 \\
\hline $\mathrm{y}=2125 \mathrm{~mm}$ & 1.807 & 1.833 & 2.417 \\
\hline
\end{tabular}

From Figs. (21, 23), it is clear that the top-slab of crossing-section bears largest stress, and presents a gradual transition to tension to both sides, and that the middle part of bottom-slab stands maximum tension, and gradually transit to pressure to both sides. This trend is the same with the solid floor. As can be seen from Fig. (22), pressure gradually becomes tension from top-slab to the bottom-slab, which is identical to the solid floor. But there exists uneven change of stress at the junctures between rids and top-slab and between rids and base plate. From Fig. (24), it shows that the overall trend of rids is the same as that of the solid floor.

\section{CONCLUSION}

After integrating the experimental study with the finite element analysis, the following conclusions can be obtained about the honeycomb-core floor:

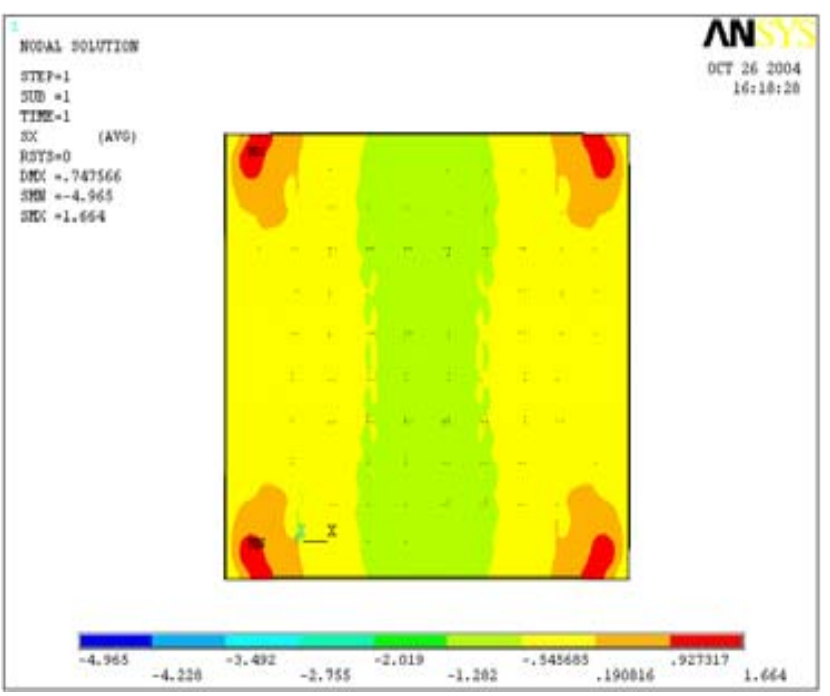

Fig. (17). $\sigma_{x}$ nephpgram of top-slab.

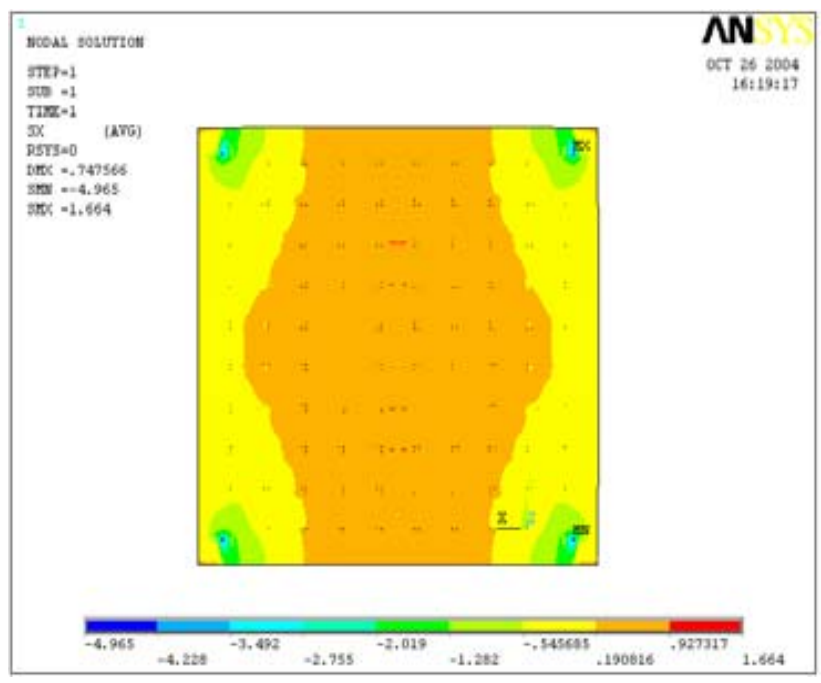

Fig. (18). $\sigma_{x}$ nephpgram of bottom-slab.

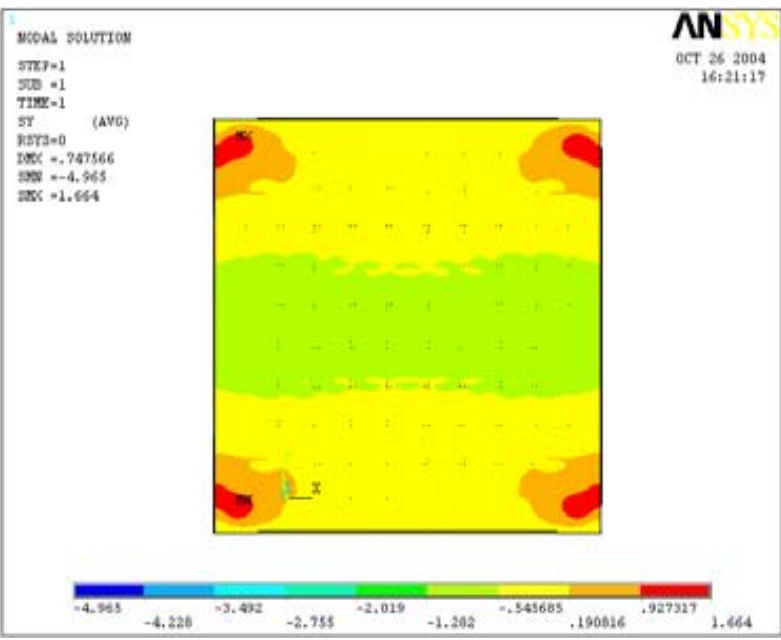

Fig. (19). $\sigma_{y}$ nephpgram of top-slab. 

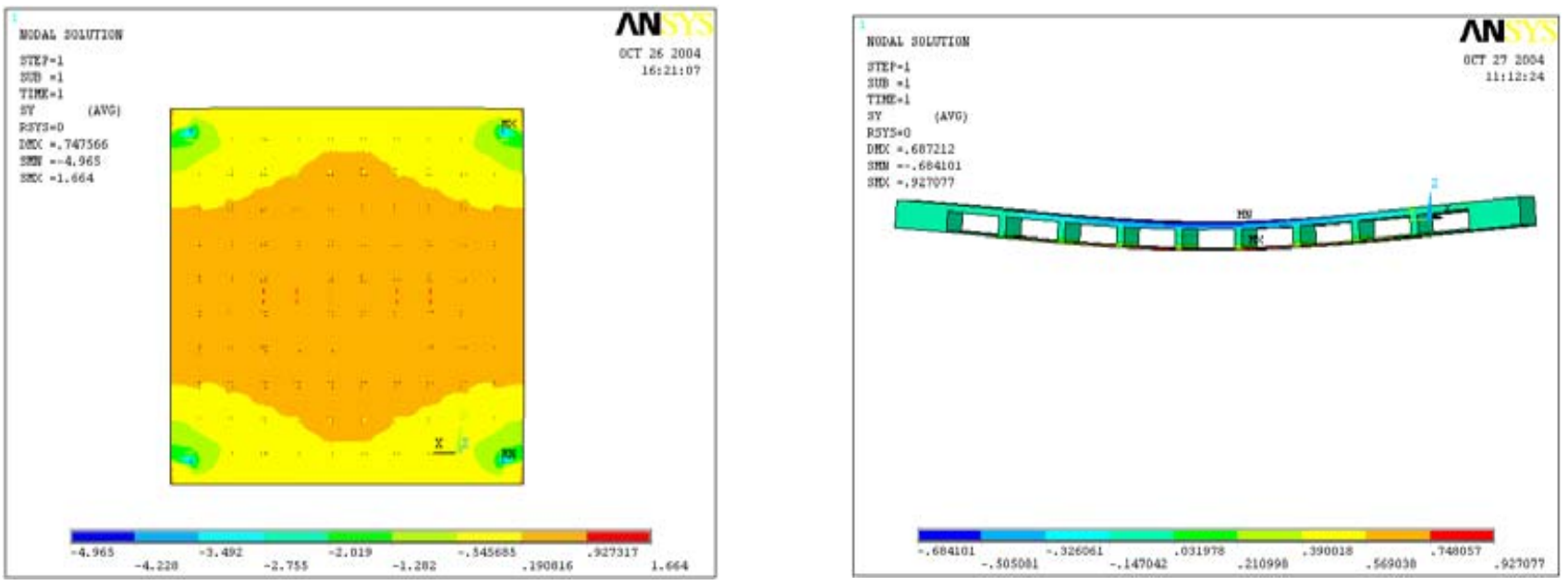

Fig. (20). $\sigma_{y}$ nephpgram of bottom-slab.
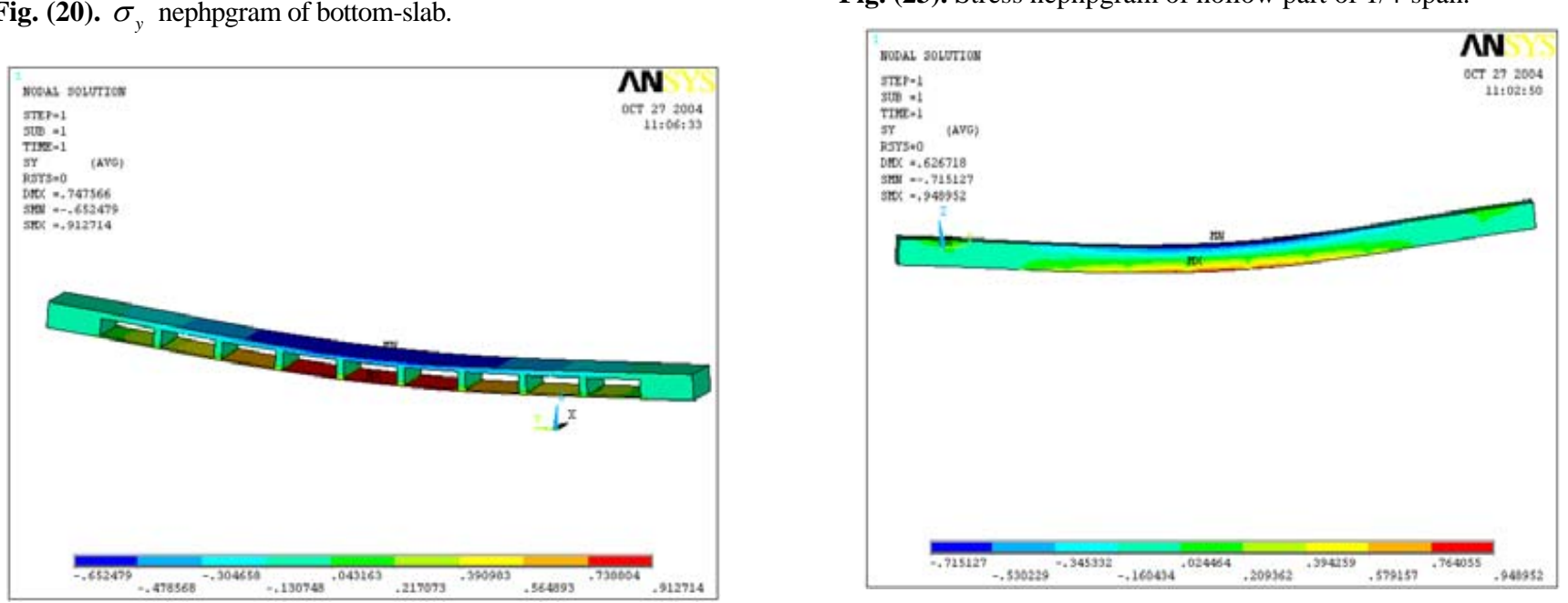

Fig. (21). Stress nephpgram of crossing-section.

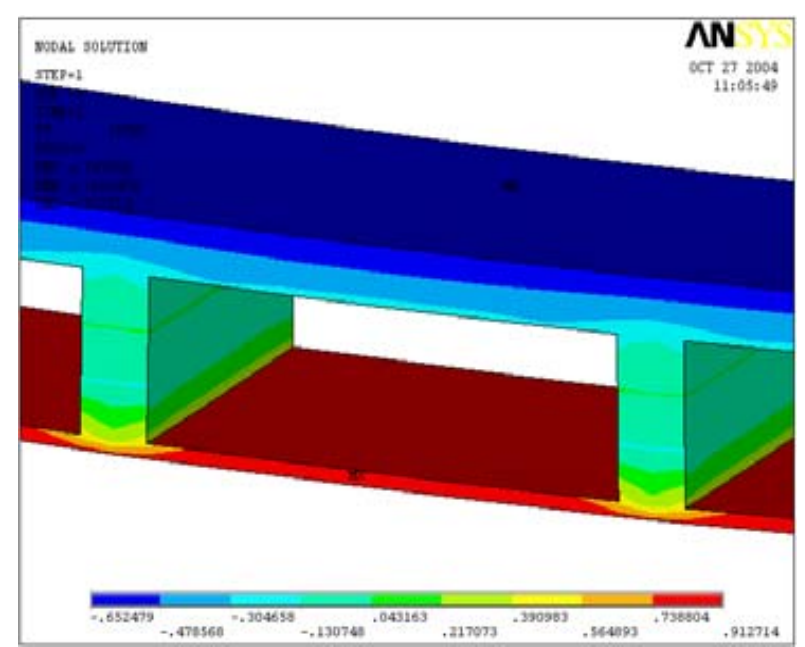

Fig. (22). Amplifier- stress nephpgram of crossing-section.

(1) Under the effect of vertical load, the bottom-slab of the honeycomb-core floor appears penetrating cracks vertically and horizontally intersected. Cracks pass through honeycombed-core module, which manifests that honeycombed-core module participates in the structure stress

Fig. (24). Stress nephpgram of solid rib of 1/4-span.

before cracking, and its adhesive property with concrete is quite good. The integrity of such floor is favorable. Therefore, in the design and analysis of the structure, it is essential to take the influence of mandrel into account.

(2) The development process of cracks, distribution, and the overall mechanical property of the honeycomb-core floor are identical to those of common solid girderless floor; its failure mode is similar to that of common solid girderless floor, as well as its biaxial bending property.

(3)From the strain value of concrete and reinforcing steel bar, the slab division of the honeycomb-core floor is in line with the method of division of typical girderless floor.

(4) Compared with the common RC floor system, the honeycomb-core floor is endowed with greater safety reserves and favorable capacity of plastic deformation. In comparison with solid floor, the deadweight decreases sharply under the circumstance that the deflection increases little, which saves the application amount of concrete greatly. Although the structural style of honeycomb-core floor is quite similar to that of the ribbed floor, the deflection of the former declines much with little increase of deadweight, which indicates that this structure has better rigidity. The design calculation of the honeycomb-core floor can not be carried out following the design method 
of ribbed floor, and otherwise it will bring about the waste of materials.

(5) The honeycomb-core floor is a floor system with light deadweight and high rigidity. As a result, it is particularly suit for large-span and large-bay building structures. And such floor structure has a wide application prospect in the architectural engineering.

\section{REFERENCE}

[1] W. Cheng, H. Jiang, Z. Gao et al. Experimental study of tubular voided flat plate floor[J]. Journal of Building Structures, vol. 25, no. 5, pp. 78-84, 2004. (In Chinese)

[2] X. Quan, H. Sun, W. Wang. Experimental study on mechanical properties of one-way model slab from cast-in-situ floor systemwith one-way cylindrical cavity[J]. Journal of Building Structures, vol. 26, no. 5, pp. 53-59, 2005. (In Chinese)

[3] W-J. Yang, X-b. Yu, Z-H. Zhang, et al. "Experimental study on simply supported slab of reinforced concrete stiffening ribbed hollow pipe girderless floor", Journal of Changsha University of Science and Technology(Natural Science), vol. 4, no. 2, pp. 21-26, 2007. (In Chinese)

[4] W-J. Yang, Z-H. Zhang, C-W. Liu, et al. Experimental Study on Simply Supported Slab of Reinforced Concrete Stiffening Ribbed
Hollow Pipe Girderless Floor[C]. Proceedings of the Ninth International Symposium on Structural Engineering for Young Experts, 2006.

[5] Z. ZHANG. The Research on the GBF Reinforced Concrete Slabs and Its Application to the Bridge Engineering[D]. Changsha: Changsha University of Science and Technology, 2006. (In Chinese)

[6] W-J. Yang, Z-H. Zhang, C-W. Liu, "Experimental Study on Mechanical Property of Stiffening-ribbed-hollow-pipe Cast-in place Reinforced Concrete Girderless Floor”, Journal of Civil Engineering and Architecture, vol. 3, no. 3, pp. 59-69, 2009.

[7] W-J. Yang, Y-H. Jiang, B. Han, et al. Experimental Study on Honeycombed-core Reinforced Concrete Hollow Floor with Four Edges Simply Supported[C]. Proceedings of the Ninth International Symposium on Structural Engineering for Young Experts, 2006

[8] W-J. Yang, Z-H. Zhang, J-H. Yin, et al. Experimental Study on Four-side Fixed-end Supported Stiffening-ribbed-hollow-pipe Reinforced Concrete Girderless Floor. The 17th National Academic Conference of Structural Engineering, pp. 181-185, 2008. (In Chinese)

[9] M. S. Hashim, Abdul-Waha, Mohammad, et al. "Rigidity and strength of orthotropic reinforced concrete waffle slabs" Journal of Structural Engineering, vol. 126, no. 2, pp. 219-227, 2000.

[10] Y. Weijun, Z. Zhenhao, M. Gaobo, "Contrast test study on reinforced concrete honeycombed-core floor and reinforced concrete multi-ribbed floor”, Building Structure, vol. 40, no. 4, pp. 107-110, 2010. (In Chinese).

(C) Yang et al.; Licensee Bentham Open.

This is an open access article licensed under the terms of the Creative Commons Attribution Non-Commercial License (http://creativecommons.org/licenses/by-nc/3.0/) which permits unrestricted, non-commercial use, distribution and reproduction in any medium, provided the work is properly cited. 